\title{
Occupational stress among Brazilian oral-maxillofacial surgeons
}

\author{
Suzana-Célia-de Aguiar-Soares Carneiro ${ }^{1}$, Belmiro-Cavalcanti-do Egito Vasconcelos ${ }^{2}$, Mirella-Marques- \\ Mercês do Nascimento ${ }^{1}$, Jefferson-Luiz-Figueiredo Leal ${ }^{3}$, Maria-do Socorro Orestes ${ }^{4}$, Gabriela-Granja \\ Porto ${ }^{1}$
}

\footnotetext{
${ }^{1} \mathrm{PhD}$ student in Oral-Maxillofacial Surgery and Traumatology at the Faculdade de Odontologia de Pernambuco. Universidade de Pernambuco, Brazil

${ }^{2}$ Adjunct Professor, PhD, Coordinator of Doctoral and Master's Programs in Oral-Maxillofacial Surgery and Traumatology at the Faculdade de Odontologia de Pernambuco. Universidade de Pernambuco, Brazil

${ }^{3}$ Specialist in Oral-Maxillofacial Surgery and Traumatology at the Faculdade de Odontologia. Universidade de Pernambuco, Brazil

${ }^{4}$ Adjunct Professor, PhD, Department of Oral-Maxillofacial Prosthetics at the Faculdade de Odontologia de Pernambuco. Universidade de Pernambuco, Brazil
}

Correspondence:

Faculdade de Odontologia de Pernambuco.

Universidade de Pernambuco.

Av. General Newton Cavalcanti, 1650

Camaragibe-Pernambuco. CEP: 54753-220

belmiro@pesquisador.cnpq.br

\author{
Carneiro SCA, Vasconcelos BC, Nascimento MMM, Leal JLF, Orestes \\ MS, Porto GG. Occupational stress among Brazilian oral-maxillofacial \\ surgeons. Med Oral Patol Oral Cir Bucal. 2009 Dec 1;14 (12):e646-9. \\ http://www.medicinaoral.com/medoralfree01/v14i12/medoralv14i12p646.pdf

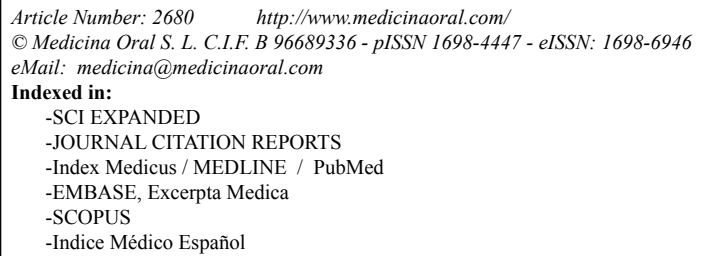

\begin{abstract}
Purpose: The aim of the present study was to assess the stress level of oral-maxillofacial surgeons, based on the Demand-Control Model. Methods: A cross-sectional study was carried out with 128 oral-maxillofacial surgeons who participated in the Brazilian Congress of Oral-Maxillofacial Surgery held in the city of Florianópolis, State of Santa Catarina, Brazil. Data was obtained using a questionnaire that incorporated the Demand-Control Model (Job Content Questionnaire), which evaluates psychosocial experiences at work. Information on age, gender and professional qualification was also collected. The data was displayed in contingency tables. The following statistical tests were used with a 5\% level of significance: chi-square test and "Fisher exact test". Results: Oralmaxillofacial surgeons were classified according to the Demand-Control Model as follows: High Demand (28\%), Low Demand (28\%); Passive Work (27\%), Active Work (16.4\%). Conclusion: The majority of oral-maxillofacial surgeons exercise their profession in unsatisfactory working conditions, as less than $1 / 3$ of the population studied worked under the ideal condition of low demand.
\end{abstract}

Key words: Stress, work, occupational health, surgery, oral. 


\section{Introduction}

Occupational stress is defined as the sum of physical, mental and physiological responses to work, which, when intensified, are transformed into negative emotional reactions. Stress significantly increases the number of workers on sick leave and is reflected in organizations as a loss of productivity and a reduction in the quality of goods and services offered (1).

The theory of stress is founded on the assessment of how the organism responds to the demands of the external environment. Stress is produced in situations in which the demands exceed an individual's capacity to respond to these stimuli. When response mechanisms are ineffective, stress is prolonged, which can have negative effects on health, such as hypertension, depression and anxiety. Regarding work issues, stress always represents a situation assessed as negative, stemming from an inability to deal with sources of pressure on the job or a disproportionate level of demands in accordance with the capacity to response to such demands.
Turner and Karasek (2) was one of the pioneering studies to search for sources of stress in social relations in the work environment and its repercussions on health. In the 1970s, he proposed a two-dimensional theoretical model that correlated two aspects - demand and control - to the risk of illness. Demand is pressure of a psychological nature and may be quantitative (work hours and pace) or qualitative (conflicts between contradictory demands). Control is the ability of a worker to employ his/ her intellectual skills in the performance of his/her job as well as having efficient authority to make decisions regarding how the work should be performed $(3,4)$.

From the relevance given to control and demand in different fields of knowledge, it became evident that there was a need to consider the two aspects simultaneously. Thus, Turner and Karasek (2) developed the DemandControl Model (DCM). This questionnaire distinguishes four basic types of work experience, generated by the interaction between the levels of psychological demand and control (Table 1).

Table 1. Questionnaire about Demands, Control and Support (short version) (6) and Demand-Control Model (3).

Demands (D) Often. Sometimes. Seldom. Never/almost never

D1. Do you have to work very fast?

D2. Do you have to work very intensively?

D3. Does your work demand too much effort?

D4. Do you have enough time to do everything?

D5. Does your work often involve conflicting demands?

Control (C) Often. Sometimes. Seldom. Never/almost never

C1. Do you have the possibility of learning new things through your work?

C2. Does your work demand a high level of skill or expertise?

C3. Does your job require you to take the initiative?

C4. Do you have to do the same thing over and over again?

C5. Do you have a choice in deciding HOW you do your work?

C6. Do you have a choice in deciding WHAT you do at work?

Support (A) Strongly agree. Mildly agree. Mildly disagree. Strongly disagree

A1.There is a calm and pleasant atmosphere where I work.

A2. We get on well with each other where I work.

A3. My co-workers support me.

A4. The others understand if I have a bad day.

A5. I get on well with my supervisors.

A6. I enjoy working with my co-workers.

\begin{tabular}{|c|c|c|}
\hline Abbreviated version of the Demand-Control Model (3) & Demand & Control \\
\hline High demand & high & Low \\
\hline Active work & high & High \\
\hline Passive work & low & Low \\
\hline Low demand & low & High \\
\hline
\end{tabular}


After a literature review, a need was perceived for studies to determine stress levels among oral-maxillofacial surgeons and classify them according to work experiences based on the Demand-Control Model (DCM) and determine significant associations between MDC groups regarding the following variables: age group, gender and professional qualification.

\section{Methods}

An epidemiological cross-sectional study was carried out with oral-maxillofacial surgeons at the Brazilian Congress on Oral-Maxillofacial Surgery and Traumatology, held in the city of Florianópolis, state of Santa Catarina, Brazil in October 2007. The sample comprised of 128 dentists who exercise the specialty of Oral and Maxillofacial Surgery, spontaneous demand. All participants agreed to respond to the questionnaire and signed terms of informed consent. The study received approval from the Research Ethics Committee (Process no. CEP/UPE 109/07 and CAAE: 0117.0.097.000-07).

During data collection, a questionnaire with three sections of questions was used. The first section contained information on demographic characteristics, such as gender, age and professional qualification. The second section contained the DCM and social support questionnaire in the abbreviated version drafted by Theörell and adapted to Portuguese $(5,6)$ (Table 1).

Among the questions in the second section that address demand, four referred to quantitative aspects (work hours and pace in the performance of the job) and one addressed qualitative aspects related to conflict. For data analysis, absolute and percentage distributions were determined for the qualitative and numeric variables. The chi-square test was employed. Fisher's exact test was used when conditions for using the chi-square test were not verified. The level of significance for all statistical tests was set at $5 \%$.

\section{Results}

One hundred and twenty eight professionals answered the questionnaire, corresponding to the total sample size. There was no loss of the sample, however it represented about $25 \%$ of the total of the participants at the Brazilian Congress on Oral-Maxillofacial Surgery and Traumatology.

Among the participants the average age was 36.78 years and $35 \%$ were between 30 and 39 years of age; $84.4 \%$ were men and $14 \%$ were women. Regarding professional qualification, 51 (39.8\%) were specialists; 41 (32\%) had master's degrees; 17 (13.3\%) were residents; and 19 $(14.8 \%)$ had doctoral degrees. In the analysis of experiences at work, High Demand and Low Demand both achieved values of $28 \%$ and Active Work achieved a value of $27 \%$.

In the analysis of age group and experiences at work, the High Demand group had a greater number of professionals from the age group of 40 or more years (36.6\%); the Active Work group had the smallest number of professionals from 30 to 39 years of age (11.1\%); the Passive Work group accounted for $14.6 \%$ of the respondents aged 40 years or more; and the Low Demand group ranged from $26.7 \%$ (30 to 39 years of age) to $30.0 \%$ (up to 29 years of age). After the application of the statistical test, no significant associations were found between age group and DCM stress groups ( $\mathrm{p}>0.05)$ (Table 2$)$.

Table 2. Assessment of age group and professional qualification according to DCM groups.

\begin{tabular}{|c|c|c|c|c|c|c|c|c|c|c|c|}
\hline \multirow{3}{*}{ Age Group } & \multicolumn{11}{|c|}{ DCM Group $^{(1)}$} \\
\hline & \multicolumn{2}{|c|}{1} & \multicolumn{2}{|c|}{2} & \multicolumn{2}{|c|}{3} & \multicolumn{2}{|c|}{4} & \multicolumn{2}{|c|}{ Group Total } & \multirow[t]{2}{*}{ p-value } \\
\hline & $\mathrm{n}$ & $\%$ & $\mathrm{~N}$ & $\%$ & $\mathrm{n}$ & $\%$ & $\mathrm{n}$ & $\%$ & $\mathrm{n}$ & $\%$ & \\
\hline Up to 29 & 5 & 16.7 & 7 & 23 & 9 & 30 & 9 & 30 & 30 & 100 & $\mathrm{p}^{(2)}=0.321$ \\
\hline 30 to 39 & 14 & 31 & 5 & 11 & 14 & 31 & 12 & 26.7 & 45 & 100 & \\
\hline 40 or more & 15 & 36.6 & 8 & 19.5 & 6 & 14.6 & 12 & 29.3 & 41 & 100 & \\
\hline TOTAL & 34 & 29 & 20 & 17 & 29 & 25 & 33 & 28.5 & 116 & 100 & \\
\hline \multicolumn{12}{|c|}{ DCM Groups $^{(1)}$} \\
\hline Class & \multicolumn{2}{|c|}{1} & \multicolumn{2}{|c|}{2} & \multicolumn{2}{|c|}{3} & \multicolumn{2}{|c|}{4} & \multicolumn{2}{|c|}{ Group Total } & p-value \\
\hline & $\mathrm{N}$ & $\%$ & $\mathrm{n}$ & $\%$ & $\mathrm{n}$ & $\%$ & $\mathrm{~N}$ & $\%$ & $\mathrm{n}$ & $\%$ & \\
\hline Specialist & 3 & 17.6 & 4 & 23.5 & 2 & 11.8 & 8 & 47 & 17 & 100 & $\mathrm{p}^{(2)}=0.587$ \\
\hline Master's & 16 & 31.4 & 6 & 11.8 & 14 & 27.4 & 15 & 29.4 & 51 & 100 & \\
\hline Doctorate & 12 & 29.3 & 8 & 19.5 & 12 & 29.3 & 9 & 21.9 & 41 & 100 & \\
\hline Resident & 5 & 26.3 & 3 & 15.8 & 7 & 36.8 & 4 & 21 & 19 & 100 & \\
\hline TOTAL & 36 & 28.1 & 21 & 16.4 & 35 & 27.3 & 36 & 28 & 128 & 100 & \\
\hline
\end{tabular}

(1) DCM groups: 1 = High demand at work; 2 = Active work; 3 = Passive work; 4 = Low demand at work.

(2) Fisher's exact test. 
Regarding professional qualification, specialists achieved the highest frequency in the Low Demand group $(47 \%)$ and the lowest frequency in the High Demand group $(17.6 \%)$; those with master's degrees accounted for $31.4 \%$ and $29.4 \%$ of the High Demand and Low Demand groups, respectively; residents accounted for $36.8 \%$ and $26.3 \%$ of the Passive Work and High Demand groups, respectively (Table 2 ). There were no significant associations between professional qualification and stress group $(\mathrm{p}>0.05)$.

\section{Discussion}

Occupational stress among healthcare professionals has been the subject of a large number of studies due to being a determinant factor of physical and mental disorders that force these professionals to take leaves of absence from their work activities. Based on the findings of the present study, oral-maxillofacial surgeons who attended the conference were predominantly in the 30to-39-year-old age group. These findings appear to indicate that both oral-maxillofacial surgeons and dental surgeons enter professional life soon after concluding their undergraduate course.

Regarding gender, the vast majority of participants were males, demonstrating that this profession still poses barriers to women. Even with the increasing participation of women in economic activities and their greater presence in the workforce, they have yet to reverse the enormous inequality with regard to gender and opportunity.

Karasek's Demand-Control Model $(2,5)$ establishes that work performed under conditions of low levels of control and high psychological demand is harmful to the health of workers and these conditions are predictors of most of the adverse reactions produced by work. In the present study, $28 \%$ pertained to the High Demand group, which is subject to fatigue, anxiety, depression and physical illness.

Analyzing the professional qualification aspect, specialists were classified with greater frequency in the Low Demand group when compared to those with master's and doctoral degrees, who, in turn, were classified with greater frequency in the High Demand group. In the literature, however, a study carried out by Luft et al. (7) entitled "The Brazilian Version of the Perceived Stress Scale: Translation and Validation for Elderly Individuals", found that higher levels of education denoted higher levels of stress (7). This finding differs from that of the present study.
Regarding residents, the highest frequencies were in the High Demand and Passive Work groups. Resident physicians may be even more susceptible to Burnout, as they experience a duality of roles and face as series of expectations on the part to their preceptors, society and even themselves. On the one hand, they are treated as students undergoing a learning process, with extenuating work days and obligatory tasks to perform; on the other hand, they must behave as complete professionals from whom responsibility, skill and efficiency are expected.

According to Turner and Karasek (2), the High Demand group leads to the majority of adverse reactions to psychological demands, such as fatigue, anxiety, depression and physical illness. Among the oral-maxillofacial surgeons in the High Demand group in the present study, approximately $36.6 \%$ were over 40 years of age. Thirty percent of those in the age group of up to 29 years were classified in the Low Demand group, which suggests that an increase in age elevates the level of worker stress in this population.

The majority of oral-maxillofacial surgeons exercise their profession in an unsatisfactory working environment, as less than $1 / 3$ of the population studies worked under the ideal condition of low demand.

\section{References}

1. Araújo TM, Aquino E, Menezes G, Santos CO, Aguiar L. [Work psychosocial aspects and psychological distress among nurses]. Rev Saude Publica. 2003;37:424-33.

2. Turner JA, Karasek RA Jr. Software ergonomics: effects of computer application design parameters on operator task performance and health. Ergonomics. 1984;27:663-90.

3. Schwartz JE, Pieper CF, Karasek RA. A procedure for linking psychosocial job characteristics data to health surveys. Am J Public Health. 1988:78:904-9.

4. Karasek RA, Theorell TG, Schwartz J, Pieper C, Alfredsson L. Job, psychological factors and coronary heart disease. Swedish prospective findings and US prevalence findings using a new occupational inference method. Adv Cardiol. 1982;29:62-7.

5. Griep RH, Chor D, Faerstein E, Werneck GL, Lopes CS. [Construct validity of the Medical Outcomes Study's social support scale adapted to Portuguese in the Pró-Saúde Study]. Cad Saude Publica. 2005;21:703-14.

6. Magnusson Hanson LL, Theorell T, Bech P, Rugulies R, Burr $\mathrm{H}$, Hyde M, et al. Psychosocial working conditions and depressive symptoms among Swedish employees. Int Arch Occup Environ Health. 2009;82:951-60.

7. Luft CD, Sanches Sde O, Mazo GZ, Andrade A. [Brazilian version of the Perceived Stress Scale: translation and validation for the elderly]. Rev Saude Publica. 2007;41:606-15. 